\title{
A herbal composition of Scutellaria baicalensis and Eleutherococcus senticosus shows vasocontrictive effects in an ex-vivo mucosal tissue model and in allergic rhinitis patients
}

\author{
Michael Katotomichelakis ${ }^{1 *}$, K. Van Crombruggen², G. Holtappels², F. A. Kuhn ${ }^{3}$, C. E. Fichandler ${ }^{3}$, \\ C. A. Kuhn-Glendye ${ }^{3}$, J. B. Anon ${ }^{4}$, C. T. Melroy ${ }^{3}$, B. Karanfilov' ${ }^{5}$, T. W. Haegen ${ }^{6}$, I. Kastanioudakis ${ }^{7}$, C. Bachert ${ }^{2}$ \\ and N. Zhang ${ }^{2}$
}

\begin{abstract}
Background: This study aimed to investigate the nasal decongestive efficacy of an alternative to pharmacotherapy, a herbal nasal spray composed of Scutellaria baicalensis and Eleutherococcus senticosus.

Methods: Scutellaria baicalensis and Eleuthrococcus senticosus and control solutions were applied separately to isolated mucosal tissue from inferior turbinates. Vasoconstriction was measured as a change in isometric tension. Moreover, twenty allergic rhinitis patients with nasal stuffiness participated in a randomized, placebo-controlled clinical study with cross-over design; the same patients served as their placebo control group. Pre-and posttreatment nasal congestion and smell test scores were evaluated for the test and placebo spray using two validated questionnaires, the 5 question nasal congestion questionnaire and the 12 question Brief Smell Identification Test-Version B.
\end{abstract}

Results: In the ex-vivo mucosal tissue, the herbal compounds were demonstrated to induce vasoconstriction when applied at $10 \mathrm{mg} / \mathrm{ml}$ concentration. The combination of $\mathrm{S}$. baicalensis and E. senticosus proved effective in relieving patients' nasal congestion and was statistically superior to placebo. No side effects were noted, and there was no difference between the pre-and post-study smell test results.

Conclusions: The combined S. baicalensis and E. senticosus herbal nasal spray relieved nasal congestion significantly better than placebo without any side effects.

Keywords: Herbal treatment, Scutellaria Baicalensis, Eleuthrococcus senticosus, Nasal congestion, Smell

\section{Background}

The nose is the predominant contact point between the respiratory system and the external environment. Its primary function is to prepare the inspired air for the lungs. It acts not only as the primary low resistance conduit for air to reach the lungs, but to humidify, cleanse and warm the inspired air to protect the more delicate tissues of the

\footnotetext{
* Correspondence: katotomihelakism@yahoo.gr

${ }^{1}$ Department of Otorhinolaryngology, Medical School, Democritus University of Thrace, Alexandroupolis, Greece

Full list of author information is available at the end of the article
}

lower airways $[1,2]$. As such, it is constantly exposed to aeroallergens, chemicals, pollutants and viral or bacterial organisms, which can induce inflammation that commonly manifests as nasal congestion or stuffiness $[3,4]$.

If the nose cannot perform its function, particularly as a low resistance air conduit due to obstruction, it adversely affects the entire organism. When the nose is obstructed, the individual's sleep is impaired, resulting in a deficit in daytime wakefulness and physical functions [5]. Chronic upper airway obstruction is frequently the presenting complaint in diseases such as allergic rhinitis (AR) and 
chronic rhinosinusitis (CRS). These are among the most common disabling diseases, and respectively account for $20 \%$ and $11 \%$ of the European adult population $[6,7]$.

The most common remedy most patients resort to for nasal obstruction is nasal decongestant sprays or drops which work via alpha-adrenergic effects; unfortunately, these are associated with rebound congestion phenomena, which lead to repeated use and subsequent "rhinitis medicamentosa" $[8,9]$. Consequently, it would be beneficial if a nasal spray could be developed based on other mechanisms, which did not have the associated rebound effects. As a result, an increasing number of patients have begun to look for an efficacious alternative, including herbal treatment options [10]. Over the last two decades interest has mounted regarding the mechanism of action of herbal therapies $[10,11]$. Many attempts to identify the active components of herbal remedies have concluded that in general no single component may be responsible for the therapeutic capacity, but rather it is a complex and intricate interaction of various herbs, which may result in therapeutic efficacy. This therapeutic efficacy needs to be thoroughly documented and confirmed in randomized, blinded placebocontrolled trials. Moreover although the majority of herbal medications are delivered orally, topical applications have also been practiced. In 2007 Jung et al. [12] found that this combination of the herbals, Scutellaria Baicalensis (Baikal skullcap) and Eleuthrococcus Senticosus (Siberian ginseng) demonstrated significant suppression of inflammatory mediators, including IL-6, TNF-a, neutrophil density and prostaglandin E2 in the mouse model [12].

These two multipurpose herbs have been used in China traditionally for treatment of inflammation, hypertension, cardiovascular diseases, bacterial and viral infections with low toxicity [13-16]. Furthermore we have demonstrated before that the combination of both herbs has a strong anti-inflammatory activity equivalent to topical steroids, and reduce the release of mediators from mast cells upon stimulation, without any impairment of nasal ciliary beat frequency in human tissue [17].

Consequently, the purposes of this study was to explore the vasoconstrictive effects of Scutellaria baicalensis and Eleutherococcus senticosus in a human nasal mucosa exvivo organ bath model and to investigate the nasal decongestant effect of a combined commercial powder solution of the two herbs compared to placebo. Furthermore, we intended to monitor side effects on the sense of smell and rebound mucosal swelling as perceived by patients.

\section{Methods}

\section{Ex-vivo nasal tissue organ bath model}

Inferior turbinates (IT) from a total of five patients (mean age 34 years, range 22 to 65 years) suffering either from allergic rhinitis, deviated septum with turbinate hypertrophy or chronic rhinosinusitis were included in the study. Mucosal tissues from IT were obtained at the Department of Otorhinolaryngology, Ghent University Hospital, during routine surgery for nasal congestion complaints. Inferior turbinate hypertrophy was diagnosed by nasal endoscopy. None of the subjects received intranasal corticosteroids, anti-histamines, anti-leukotrienes, oral or intranasal decongestants, or intranasal anticholinergics within the 2 weeks prior to surgery. None of the subjects received oral and/or intramuscular corticosteroids within the 4 weeks prior to surgery. The ethical committee of the Ghent University Hospital approved the study, and all patients completed an IRB approved informed consent.

\section{IT tissue preparation}

The inferior turbinates collected during surgery were immediately transported to the laboratory and placed in cold physiological salt solution (PSS in $\mathrm{mM} ; \mathrm{NaCl}: 118.5$, $\mathrm{KCl}: 4.8, \mathrm{CaCl}_{2}: 1.9, \mathrm{MgSO}_{4}: 1.2, \mathrm{NaHCO}_{3}: 25, \mathrm{KH}_{2} \mathrm{PO}_{4}$ : 1.2 and glucose: 10.1). The bony structures were carefully removed and 8 full-thickness strips $(3 \times 15 \mathrm{~mm})$ were cut along the transverse axis.

\section{Isometric tension recording}

The strips -prepared as describe above- were mounted in $10 \mathrm{ml}$ organ baths containing aerated $\left(5 \% \mathrm{CO}_{2}\right.$ in $\left.\mathrm{O}_{2}\right)$ PSS, maintained at $37^{\circ} \mathrm{C}$.

Vasodilatation (responsible for nasal congestion) and vasoconstriction (relief of nasal congestion) were measured as a change in isometric tension by means of a MLT0201 force transducer (Panlab, Spain) attached to a Power lab/8sp data recording system (AD Instruments, U.K.). The signals were captured and analysed with Lab Chart 6 Pro software.

Because nasal mucosa contains no contractile elements other than the smooth muscles of the blood vessels, the changes in isometric tension in this tissue are exclusively mediated by the vascular smooth muscle cells. Relaxations consequently equal vasodilatation and contractions are vasoconstrictions.

\section{Patients study group}

This study was conducted in 2011 as a double-blind placebo-controlled randomized cross-over trial (DBPCR). Twenty allergic rhinitis (AR) patients (mean age 55 years, range 24 to 67 years) whose presenting complaint was nasal stuffiness participated in the study. The inclusion criteria were age $\geq 18$ years, male or female, current complaint of nasal congestion for $>4$ weeks. Exclusion criteria were nasal polyps, an acute viral URI or bacterial infection. The same patients were used as the placebocontrol (CO) group. Diagnosis of AR was based on history of nasal stuffiness, nasal endoscopy and skin prick test (SPT) with a battery of common aeroallergens. Only subjects who fulfilled the criteria of AR according to the 
ARIA guidelines [18] and were sensitized exclusively to $H D M$, grass and tree pollens were included. The Memorial Health University Hospital Research Committee of 2011 approved the study and all patients completed an IRB approved informed consent before participating in the prospective, randomized, double blind, placebo-controlled crossover study.

The Test Spray (provided by BreatheZen, Znova LLC, Pikesville, MD, USA) contained the two herbs Scutellaria baicalensis and Eleuthrococcus senticosus, in solution with potassium sorbate and ascorbic acid in Ringer's lactate solution; the placebo spray included all elements aside from the two herbs, including Ringer's lactate solution, potassium sorbate, and ascorbic acid. The test and placebo sprays were randomly assigned to bottles A\&B in order to vary the starting order of drug or placebo. The contents of bottles A\&B were blinded to both patient and clinical examiner. The patients sprayed each nostril twice, $3 \mathrm{x}$ per day with bottle A for 7 days, did not spray for 3 days as a "wash out" period and then sprayed each nostril twice, $3 \mathrm{x}$ per day with bottle B for 7 days. Three days were chosen to have no remaining effect from the ingredients of bottle A ( $>5$ times the half-life of the anti-obstructive effect).

At the start and the end of the study periods A and B, patients were asked to fill in two validated widely used questionnaires for nasal congestion evaluation, the 5 question nasal congestion questionnaire [19] and the 12 question Brief Smell Identification Test-Version B [20]. Both questionnaires were administered before the study, after bottle A and after bottle B. Pre-and post-treatment nasal congestion scores as well as smell test scores were evaluated for verum (test spray) and placebo sprays, and side effects were monitored. The 5 question nasal congestion questionnaire (CQ5) is derived from the CQ7, which is reliable, valid, and responsive to differences in severity of nasal congestion. However, a MCID has not been elaborated.

\section{Statistical analysis}

A Wilcoxon test for paired samples was used to reveal improvement from baseline with both the herbal spray and placebo. The Mann-Whitney $U$ test was used for between-group (unpaired) comparisons. $P$ values of less than 0.05 were considered statistically significant.

\section{Results}

\section{Nasal mucosal tissue organ bath model}

$10 \mathrm{mg} / \mathrm{ml}$ Eleutherococcus senticosus, equivalent to the formulation of the spray, induced a vasoconstrictive response in nasal mucosal strips similar in magnitude to vasoconstrictive stimuli such as electrical field stimulation (EFS; $8 \mathrm{~Hz}$ ) and $10^{-6} \mathrm{M}$ phenylephrine. Given the fact that in patients allergic to $H D M$ the response to exogenous applied allergen still clearly induced a relaxation indicates that the action by Eleutherococcus senticosus is exclusively vasoconstrictive and not inhibitory against allergen-induced responses (Fig. 1). The contractions by Eleutherococcus senticosus are not mediated via a similar mechanism of action as traditional nasal decongestions as interference with adrenoceptor-related mechanisms by means of guanethidine and phentolamine have no effect on the magnitude of the contraction. The exact mechanism of action remains unknown but the involvement of prostaglandins or neuronal components that indirectly release other contractile substances could be excluded as indomethacin and tetrodotoxin was ineffective, respectively.

The nasal mucosal tissue showed normal responses to know stimuli such as EFS, $15 \mathrm{~V}, 8 \mathrm{~Hz}, 20 \mathrm{~s}$, and phenylephrine $10^{-6} \mathrm{M}$, and HDM-induced relaxation (Fig. 2).

Scutellaria baicalensis could not be tested in the organ bath model due to foam formation.

\section{Patients DBPCR trial}

All patients completed the study schedule, receiving two treatments (randomized selection of test sprays first or placebo spray first) and a 3 day wash-out period in between the treatment phases in a cross-over study design. There was a significant improvement from baseline nasal stuffiness with both the herbal spray ( $p=$ $0.0002)$ and placebo spray $(p=0.002)$ (Fig. 3). Furthermore, the change from baseline was significantly superior for the Herbal spray compared to placebo, and the two groups were significantly different at end of treatment in relieving nasal congestion $(p=0.026)$ (Wilcoxon Test for paired samples).

17/20 patients completed all 3 smell tests. The pre-test score total for all patients was 172 (improvement of 0.33 /patient). Most patients had the same score before and after the study, a few patients had an improved score, none had a decreased score. There was consecutively no change in the smell test results with either spray, nor any significant differences between the prestudy and post-study smell test results. There were no adverse events reported from either treatment. No patient developed rhinitis medicamentosa-like symptoms (rebound congestion) from continued use of either spray, nor after cessation of use.

\section{Discussion}

Nasal congestion is a quality of life concern that variably affects every individual [6]. When this becomes chronic, several systemic or topical decongestants are available, but all have undesired side effects. Topical nasal decongestants commonly produce rhinitis medicamentosa $[8,9]$. Oral decongestants may be also a problem for patients with hypertension, pulmonary disease or prostate hypertrophy. 


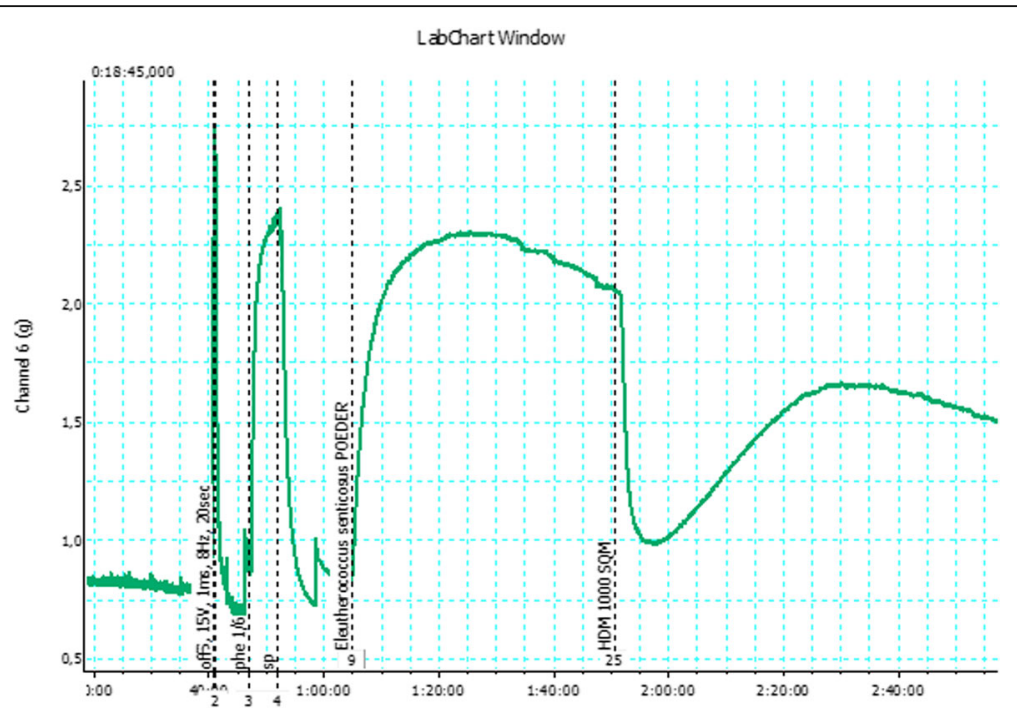

Fig. 1 Responses to electricfield stimulation (EFS, $8 \mathrm{~Hz}$ ) and the know vasoconstrictor phenylephrine $\left(10^{-6} \mathrm{M}\right)$, followed by response to Eleutherococcus senticosus (10 mg/ml) and HDM (1000 SQM)

Nasal saline irrigations, which have become very popular may in fact interfere with ciliary beat frequency. Unal et al. [3] found that patients who used post operative Ringer's lactate irrigation, had significantly better mucocillary transport times than patents using isotonic saline. They concluded that Ringer's lactate is a better solution for nasal irrigation than $0.9 \%$ saline.

Scutellaria baicalensis and Eleuthrococcus senticosus are two herbs, which have been used for many years in Eastern medicine and have recently been shown to have strong anti-inflammatory effects [13-16]. Specifically, in our previous study in a human nasal mucosal model we found that the combination of these two herbs suppresses PGD-2, histamine, IL-5 and proinflammatory cytokines equal to or better than fluticasone nasal spray [17]. Our conclusion was that the combination of S. baicalensis and E. senticosus may be able to significantly block allergic early-and late-phase mediators and substantially suppress the release of proinflammatory and Th1-, Th2-, and Th17- derived cytokines [17]. This suggests that the combination of Scutellaria baicalensis and Eleuthrococcus senticosus may be as good

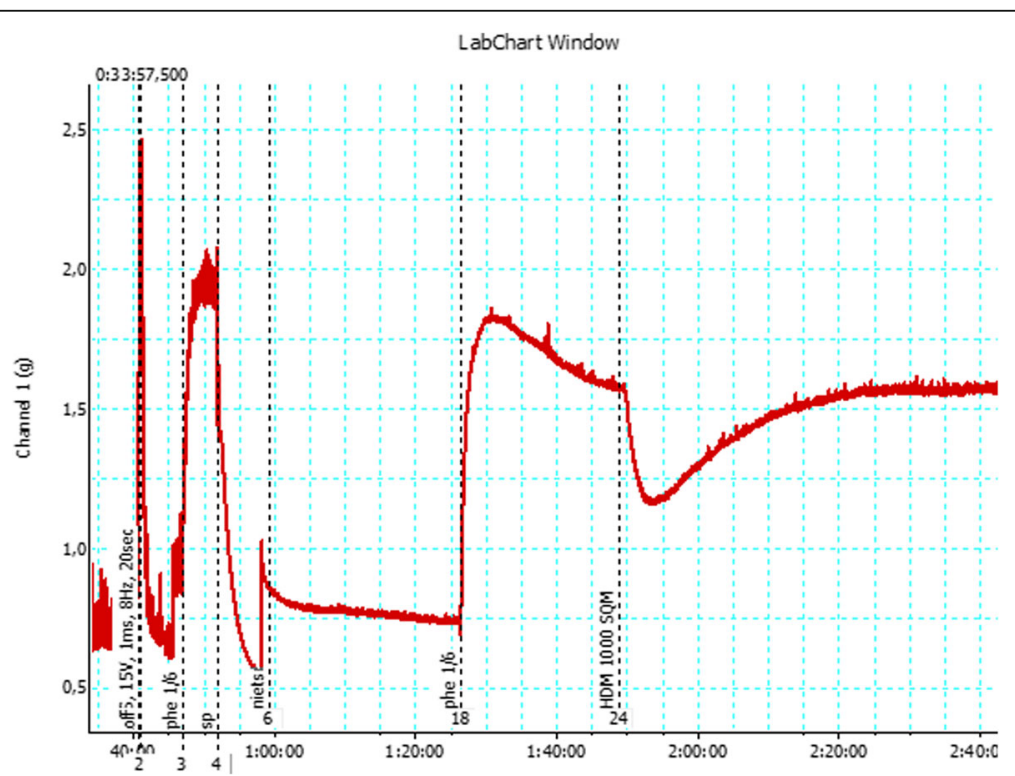

Fig. 2 Positive controls: normal responses to EFS $(8 \mathrm{~Hz})$ and phenylephrine $\left(10^{-6} \mathrm{M}\right)$ followed by response to HDM (1000 SQM) on a phenylephrine-precontracted tissue 


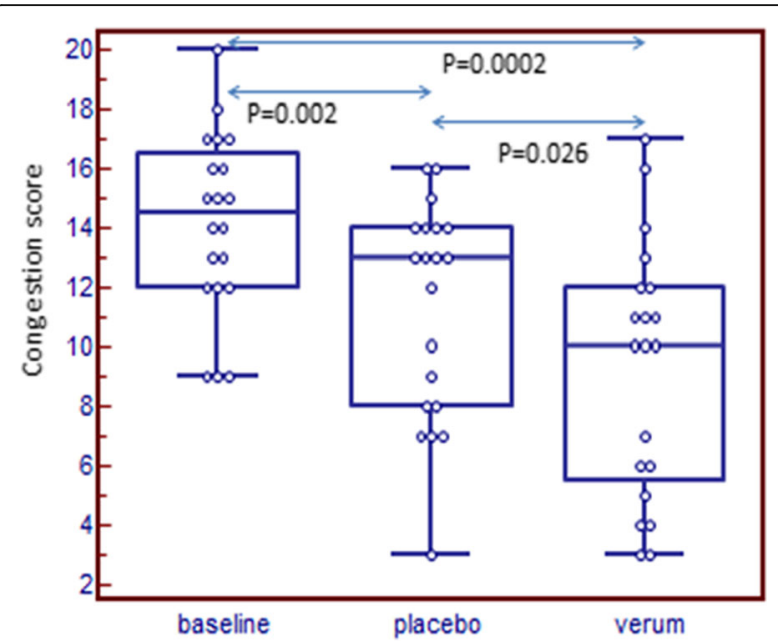

Fig. 3 Congestion score improvement from baseline with the herbal spray (verum) and placebo spray

as nasal corticosteroid sprays in controlling allergic rhinitis, without the concern for HPA axis suppression. Further studies will be required to establish this.

The purpose of this study was to demonstrate that these herbal compounds reduce nasal congestion. Indeed, we found significant improvement of the 5 question nasal congestion questionnaire scores [19]- in patients who used the herbal nasal spray, compared to the placebo control group $(p=0.026)$ and to the baseline score $(p=0.0002)$. The Smell Test demonstrated no difference between the pre and post study smell test results (Brief Smell Identification Test-Version B [20].

Furthermore, experiments in ex vivo human mucosal tissue from inferior turbinates showed Eleutherococcus senticosus to induce a vasoconstrictive response when given to an organ bath setup. This vasoconstrictive effect at $10 \mathrm{mg} / \mathrm{ml}$ was similar in magnitude to vasoconstrictive stimuli such as electrical field stimulation (EFS; $8 \mathrm{~Hz}$ ) and $10^{-6} \mathrm{M}$ phenylephrine.

The given data in this study reveal that the herbal spray is safe for nasal use and effectively reduces nasal congestion more significantly than the base solution of Ringer's lactate, vitamin $\mathrm{C}$ and potassium sorbate. It does not affect the patients' sense of smell and does not cause any rebound nasal congestion. The clinical application of this herbal spray has the potential to benefit a wide array of patients who suffer from nasal congestion, but do not want the rebound phenomena associated with other nose sprays or cannot use oral decongestants secondary to comorbidities or paradoxical side effects. The potential antibacterial and possible antiviral properties and its anti-inflammatory effect, make this an attractive alternative to current nasal decongestant sprays. Further studies are needed to more completely evaluate this herbal medication's efficacy and range of application.

\section{Conclusion}

We found that the Scutellaria baicalensis and Eleuthrococcus senticosus herbal nasal spray relieved nasal congestion in a mucosal model and in clinic significantly better than placebo without any reported rebound effect and no effect on the sense of smell. The potential uses for this spray include use in acute and chronic sinusitis, allergic rhinitis, viral upper respiratory infections and even peri-operative application. Further evaluation of the safety and efficacy of this herbal spray in rhinitis patients is pending.

\section{Abbreviations}

AR: Allergic rhinitis; CO: Control; CQ5: 5 question nasal congestion questionnaire; CRS: Chronic rhinosinusitis; DBPCR: Double-blind placebocontrolled randomized cross-over trial; EFS: Electrical field stimulation; IT: Inferior turbinates; SPT: Skin prick test; URI: Upper respiratory infection

\section{Acknowledgements}

Not applicable.

\section{Funding}

No funding

\section{Availability of data and materials}

Upper Airways Research Laboratory (URL), Ghent University Hospital, Belgium.

\section{Authors' contributions}

KM and $\mathrm{KI}$ analyzed the data and drafted manuscript; VCK and HG carried out the human nasal mucosa ex-vivo organ bath model and drafted manuscript; KA, FCE, KGCA and MCT participated in the design of the study, carried out the double-blind placebo-controlled randomized cross-over trial in patients, and analyzed the data; AJB, KB and HTW participated in the design of the study and coordination and drafted manuscript; $B C$ and $Z N$ designed, conceived the study and coordination, analyzed the data and drafted manuscript. All authors read and approved the final manuscript.

\section{Consent for publication}

The ex-vivo nasal tissue organ bath model study was approved by the ethical committee of the Ghent University Hospital and all patients completed an IRB approved informed consent and the double-blind placebo-controlled randomized cross-over trial (DBPCR) in patients was approved by the Memorial Health University Hospital Research Committee of 2011 and all patients completed an IRB approved informed consent before participating, as well.

\section{Competing interests}

The authors declare that they have no competing interests.

\section{Publisher's Note}

Springer Nature remains neutral with regard to jurisdictional claims in published maps and institutional affiliations.

\section{Author details}

${ }^{1}$ Department of Otorhinolaryngology, Medical School, Democritus University of Thrace, Alexandroupolis, Greece. ${ }^{2}$ Upper Airways Research Laboratory (URL), Ghent University Hospital, Ghent, Belgium. ${ }^{3}$ Georgia Nasal \& Sinus Institute, Savannah, GA, USA. ${ }^{4}$ ENT Specialists of Northwest Pennsylvania, Erie, PA, USA. ${ }^{5}$ Ohio Sinus Institute, Dublin, OH, USA. ${ }^{6}$ Arizona Sinus Center, Phoenix, AZ, USA. ${ }^{7}$ Department of Otorhinolaryngology, Medical School, University of loannina, loannina, Greece. 
Received: 18 April 2017 Accepted: 13 November 2017

Published online: 29 November 2017

\section{References}

1. Geurkink N. Nasal anatomy, physiology, and function. J Allergy Clin Immunol. 1983;72:123-8.

2. Bachert C. Clinical aspects of environmental illnesses of the nose and paranasal sinuses-science and clinical practice. Eur Arch Otorhinolaryngol Suppl. 1996;1:73-153.

3. Unal M, Görür K, Ozcan C. Ringer-lactate solution versus isotonic saline solution on mucociliary function after nasal septal surgery. J Laryngol Otol. 2001;115:796-7.

4. Naclerio RM, Bachert C, Baraniuk JN. Pathophysiology of nasal congestion. Int J Gen Med. 2010;3:47-57.

5. Osborn JL, Sacks R. Chapter 2: nasal obstruction. Am J Rhinol Allergy. 2013; 27(Suppl 1):S7-8.

6. Bachert C, Van Cauwenberge P, Olbrecht J, Van Schoor J. Prevalence, classification and perception of allergic and nonallergic rhinitis in Belgium. Allergy. 2006;61:693-8.

7. Hastan D, Fokkens WJ, Bachert C, et al. Chronic rhinosinusitis in Europe-an underestimated disease. A GA2LEN in study. Allergy. 2011;66:1216-23.

8. Ramey JT, Bailen E, Lockey RF. Rhinitis medicamentosa. J Investig Allergol Clin Immunol. 2006;16:148-55.

9. Scadding GK. Rhinitis medicamentosa. Clin Exp Allergy. 1995;25:391-4.

10. Li XM, Brown L. Efficacy and mechanisms of action of traditional Chinese medicines for treating asthma and allergy. J Allergy Clin Immunol. 2009;123: 297-306.

11. Eisenberg DM, Kessler RC, Foster C, Norlock FE, Calkins DR, Delbanco TL. Unconventional medicine in the United States. Prevalence, costs, and patterns of use. NEJM. 1993;328:246-52.

12. Jung SM, Schumacher HR, Kim H, Kim M, Lee SH, Pessler F. Reduction of urate crystal-induced inflammation by root extracts from traditional oriental medicinal plants: elevation of prostaglandin D2 levels. Arthritis Res Ther. 2007:9:R64.

13. Huang $\mathrm{CH}$, Kimura R, Bawarshi-Nassar R, Hussain A. Mechanism of nasal absorption of drugs. II: absorption of L-tyrosine and the effect of structuralmodification on its absorption. J Pharm Sci. 1985;74:1298-301.

14. Gulla J, Singer AJ, Gaspari R. Herbal use in ED patients. Acad Emerg Med. 2001:8:450.

15. Eisenberg DM, Kessler RC, Foster C, Norlock FE, Calkins DR, Delbanco TL. Unconventional medicine in the United States. Prevalence, costs, and patterns of use. N Engl J Med. 1993;328:246-52.

16. Ueda S, Nakamura H, Masutani H, Sasada T, Takabayashi A, Yamaoka Y, Yodoi J. Baicalin induces apoptosis via mitochondrial pathway as prooxidant. Mol Immunol. 2002;38:781-91

17. Zhang N, Van Crombruggen K, Holtappels G, Bachert C. A herbal composition of Scutellariabaicalensis and Eleutherococcussenticosus shows potent anti-inflammatory effects in an ex vivo human mucosal tissue model. Evid Based Complement Alternat Med. 2012;2012:673145.

18. Bousquet J, Khaltaev N, Cruz AA, et al. Allergy. 2008;63(Suppl 86):8-160.

19. Stull DE, Meltzer EO, Krouse JH, Roberts L, Kim S, Frank L, Naclerio R, Lund V, Long A. The congestion quantifier five-item test for nasal congestion: refinement of the congestion quantifier seven-item test. Am J Rhinol Allergy. 2010;24:34-8.

20. Doty RL, Marcus A, Lee WW. Development of the 12-item Cross-Cultural Smell Identification Test (CC-SIT). Laryngoscope. 1996;106:353-6.

\section{Submit your manuscript to a SpringerOpen ${ }^{\circ}$ journal and benefit from:}

- Convenient online submission

- Rigorous peer review

Open access: articles freely available online

- High visibility within the field

Retaining the copyright to your article 